\title{
Improving of the quality and reliability of water supply systems on the basis of modern information and computing technologies ${ }^{*}$
}

\author{
Aleksandr V. Alekseev ${ }^{1, \dagger}$ \\ ${ }^{1}$ Melentiev Energy Systems Institute of Siberian Branch of the Russian Academy of Sciences (ESI \\ SB RAS), Pipeline Energy Systems Department, 130, Lermontov str., Irkutsk, Russia, 664033
}

\begin{abstract}
The article deals with the issues of increasing the reliability and quality of water supply systems operation on the basis of modern methods and software complexes for the analysis and development of hydraulic conditions. Against the backdrop of the analysis of the literature on the problem of reliability, the relevance and insufficiency of attention to maintaining the required level of reliability at the stage of water supply systems operation are revealed. The main factors that affect on operational reliability are considered. These factors are largely associated with the competent organization of operating conditions of water supply systems. A brief description of the «Angara-WS» computer program for solving the problems of analyzing and developing of hydraulic conditions, as well as the experience of its practical application, is given. A special feature of this complex is its universality, the possibility of multilevel representation of models, the execution of one- and multi-level calculations, integration into a common information space of the enterprise, automation of the processes of mode analysis, accumulation and analysis of damage statistics.
\end{abstract}

\section{An analysis of literature and problem statement}

In Russia there are more than $577000 \mathrm{~km}$ of centralized water supply systems, about $60 \%$ of them have significant physical depreciation, one third of them requires urgent replacement. At the same time, only $1.6 \%$ of the total length of pipelines is replaced per year [1]. In these conditions, the maintenance of reliable and high-quality water suppling of consumers is complicated. A reliable water supply is understood as the ability of the water supply system (WSS) to provide consumers with water in the applied volume with the required parameters at any time. In the Russian normative documents there are no indicators of reliability of the WSS and their subsystems and also there is no a single interpretation of the WSS reliability term. The only requirement for the reliability of the WSS operation is the requirement of constant quality supply of all consumers with water.

\footnotetext{
* The research was carried out within the project III.17.4.3 of the Fundamental research program of SB RAS (AAAA-A17-117030310437-4)

†Corresponding author: asanya@mail.ru
} 
However, construction rules [2] allow a short-term reduction in the supply of consumers in emergency conditions up to $30 \%$ of the volume of water supply.

The main causes of accidents in WSS that invoke a reduction of supply level to consumers are: the rupture of pipelines, damage of shut-off and connecting devices, disconnection of power supply to pumping stations and water intake facilities. There are following main types of pipeline damages: mechanical (construction works near water lines, design errors, soil subsidence), corrosive (for steel and cast iron pipes crack formation is typical), welded seam fractures (defective welding, pipeline deflection, temperature stresses). Each WSS has its own typical causes of accidents, depending on climatic and operating conditions, water quality, etc. On average, the frequency of failures in Russian WSS is in the range 0.5 to 2 accidents per $1 \mathrm{~km}$ of the pipeline per year [3].

The problem of WSS reliability arises during the design of systems and in their operation. Reliability of WSS operation is closely connected with the concepts of controllability and manufacturability.

Reliability of WSS during design can be improved by: network ringing, duplication of pipe sections, increasing their diameter, choosing the most suitable for these operating conditions of pipeline material, building backup water sources, installing backup and emergency pumping units, connecting pumping stations to various electrical substations, installation of reservoirs, emergency automatics, accounting for the planned prospective load of consumers, etc. This allows for the operation phase eliminate some of the accidents in WSS without limiting of consumers supplying.

The operational reliability of WSS is determined both by the reserves set at the design stage and by the operating conditions. As is known, the process of water consumption has a stochastic character, as a result of which the WSS constantly functions under changing parameters conditions (pressure, flow, concentration of disinfectants, etc.) and regimes. The reliability of WSS largely depends on the permissibility of operating conditions. Ensuring of permissibility of operating condition is observance of technological requirements of state parameters for each networks elements. The further the values of the mode parameters are from the boundary values, the higher the reliability of the system operation. Or, in other words, the permissibility of the operating conditions is a necessary condition for ensuring the reliability of the regime. Thus, the organization of hydraulic regimes has the greatest impact on operational reliability. In addition, quality and timeliness of repair and diagnostic works affect to the operational reliability.

The issues of increasing the reliability of the existing WSS are the subject of a large number of works, the main part of which deals with the selection of pipe materials, equipment and optimal terms of their operation. Il'in $\mathrm{Yu}$. A. made a significant contribution to the study of reliability problems of WSS [4 and others]. Among modern publications, it is possible to single out the works of Galperin E.M. [5, etc.], which consider ways to improve the reliability of WSS through the use of polythene pipes as the most reliable and having a short repair time. In [6], the problem of increasing of the failures number in WSS in connection with the aging of equipment is considered and a technique for switching from an unsteady flow of failures to a stationary one is proposed, which makes it possible to use simpler engineering approaches to assess system reliability. The article [7] proposes a methodology for WSS reliability accounting in planning of the system development. In work [8] the technique of an estimation of probability of fault-free consumers supplying in with a glance to the probabilities of WSS failures and probabilistic character of water consumption is offered. This technique is based on the decision of a flow distribution with pressure-driven demand. The study [9] shows the dependence of the number of accidents on the pipeline, depending on its material, diameter and average pressure. In work [10] the technique of calculation of WSS reliability and quality indicators on the basis of hydraulic calculations on the aggregated model is offered. For a number of territories, seismic activity 
is one of the significant factors affecting to the WSS reliability. The account of seismic effects on the WSS reliability is given in $[11,12]$. In all mentioned works, the reliability assessment of a particular system is reduced to multivariate hydraulic calculations and the need to develop a mathematical model or programs for hydraulic modeling (or adaptation of existing products such as EPANET [13]). At the same time, the authors do not pay enough attention to the permissibility of the regimes, confining themselves to checking of the level of consumers supplying. Thus, without using high-quality universal computer programs for modeling the hydraulic regimes of WSS operation, it is impossible to estimate their reliability exactly.

\section{Brief description of the information-computer complex "ANGARA-WS"}

Software for automating development of operational conditions for various types pipeline systems has been creating and implementing in ESI SB RAS for many years [14]. For the WSS simulation, the information-computer complex (ICC) "ANGARA-WS" (actual version 1.5) was developed, consisting of the information-computer environment "ANGARA" $[15,16,17]$ and a set of calculation modules. The graphical interface of the ICC "Angara-WS" is shown in Fig.1. The main purpose of the ICC "ANGARA-WS 1.5"

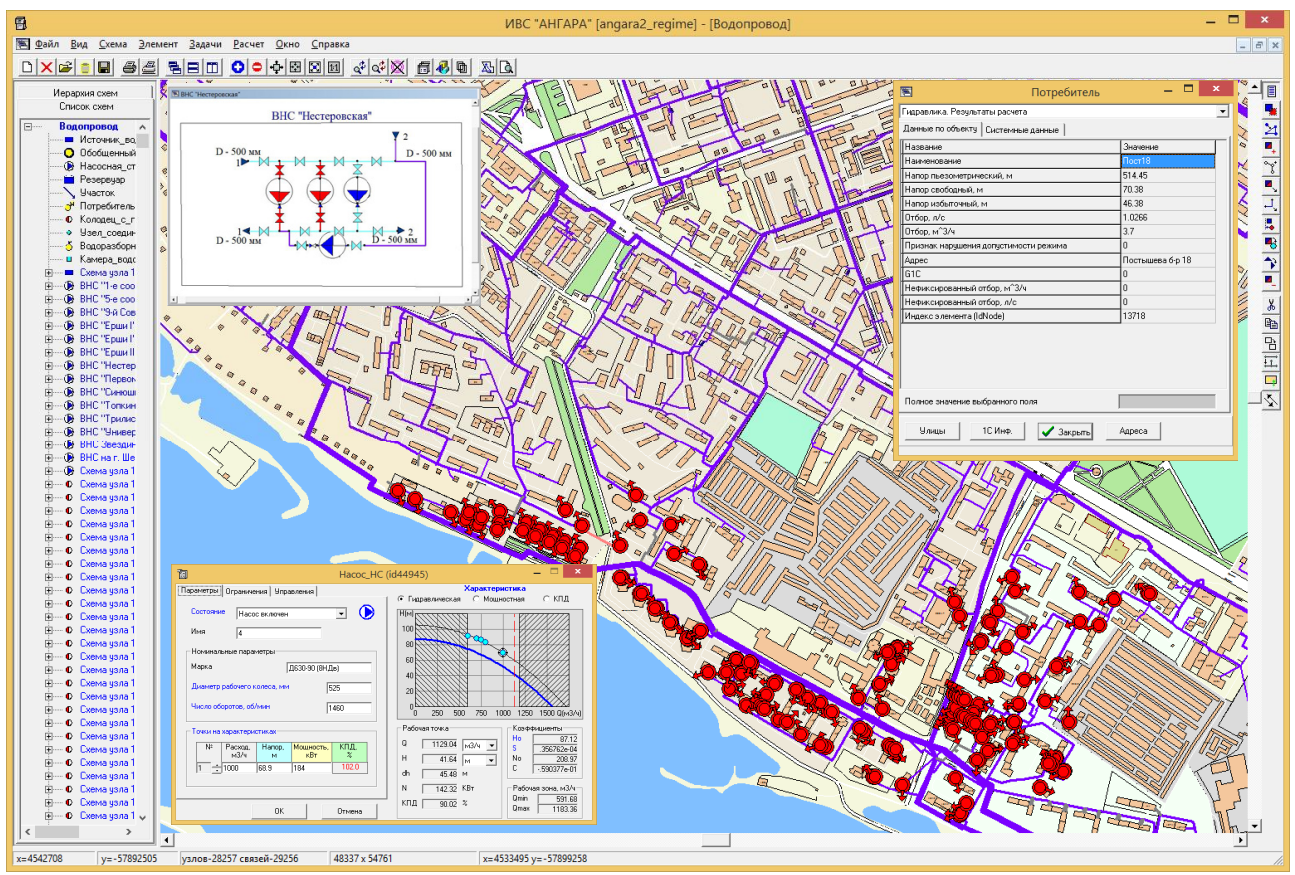

Fig. 1. Interface of the ICC "ANGARA-WS".

$[18,19]$ is to automate the processes of operational conditions development (normal, emergency, post-emergency) of water supply networks of arbitrary configuration (branched, multi-loop), structures (with any number and location of sources, pumping stations, reservoirs, pressure and flow regulators and other elements) of any dimension. The program allows to organize the calculation scheme, both in single-level and in multi-level form [20]. At the same time, it is possible to carry out both the calculation of a single level (for example, main or distribution network) and a multilevel calculation of the WSS regime 
as a whole. ICC makes it possible to perform: the calculation of the flow distribution with fixed demand (analysis of the network capacity at given loads of consumers); flow distribution with pressure-driven demand (analysis of the degree of consumer delivery at given network structure and characteristics); calculation of the operation conditions of pumping stations, piezometric graphs, permissibility conditions analysis.

\section{Experience of ICC "ANGARA-WS" application in MUP "Vodokanal" Irkutsk city}

Municipal unitary enterprise (MUE) "Vodokanal" operates water supply and sewerage networks in Irkutsk. The length of water supply networks on the balance of the MUE "Vodokanal" is $774 \mathrm{~km}$; of sewerage network is $759 \mathrm{~km}$, as well as 14 reservoirs, 22 waterpumping stations and 1794 fire hydrants. Irkutsk is located in a zona of high seismic activity and characterized by a complex terrain (geodetic marks of consumers are in the range of $420-510 \mathrm{~m}$ ). The water supply network is divided into 17 zones with reduced or increased pressure [21].

The ICC "ANGARA-WS" is the basis of the automated working station of the operation conditions calculation engineers. The introduction of ICC in the group for conditions calculation in MUE "Vodokanal" in Irkutsk allowed:

1) to create and maintain a common database and an electronic calculation model for Irkutsk city. This model consist of water supply networks schemes (about 35000 nodes), network structures schemes (more than 10000 schemes) and sewage networks schemes (more than 65000 nodes);

2) to organize the access of various departments and services of the enterprise to this information;

3) to integrate the ICC into the common information space of the enterprise [22], that made it possible to avoid duplication and inconsistency of information in various departments of the enterprise.

For the dispatch service, the dispatching log "calls and damages" was developed. It allows to accumulate and analyze statistics on the damageability of the WSS, identify specific factors and conditions, and then take these factors into account in the design and development of WSS. Using this statistic, it becomes possible to calculate the probability of fault of system elements. Another important problem of the dispatcher's log is to maintain the database of WSS in the current state (by registering of all valves switching in the network).

After calibration of the obtained hydraulic model, a series of calculations were performed on it, analysis of which revealed:

1) the presence of a significant number of violations on the permissibility of the hydraulic regime, in particular, the excess of the maximum permissible head in the network; (consumers with excessive pressure, the required and actual characteristics of the pumping station are shown in Fig. 1);

2) the presence of closed circulation circuits around several pumping stations;

3) several closed valves in the network;

4) the most emergency parts of the network.

To increase the reliability and reduce pressure in WSS, the zoning scheme was revised, permissibility of hydraulic conditions was ensured. This allowed to stop 2 pump stations, to reduce pressure at others pumping stations and to determine the locations for pressure regulators setting. These events were held on WSS of Irkutsk in 2013-2014. These allowed significantly (about 25\%) to reduce the fault rate in WSS in last years (Fig. 2a). In addition, it let to reduce the level of leakages in the network, the cost for electricity at pumping stations and improve the quality of WSS operation in general. The installation of pressure 
regulators allowed to reduce and stabilize the pressure in the most complex fragments of the network (Fig. 2b), that also positively affected on the WSS reliability.

Providing operational access to all employees of the enterprise to common information (including geo-information) allowed to reduce the time of registration and response on calls for damages and as a result the time of their repair. Analysis of statistics on the fault rate of pipelines showed that the greatest number of accidents fall on steel and cast-iron pipes. These accidents are caused by various factors: corrosion, subsidence, seismic action, etc. As a result, it was decided to gradually switch to polyethylene pipes. Recent years MUE has been working to replace the most emergency sections of the network with pipes from this material. For today, more than $144 \mathrm{~km}$ of pipes (19\% of the total length) have been replaced [23].

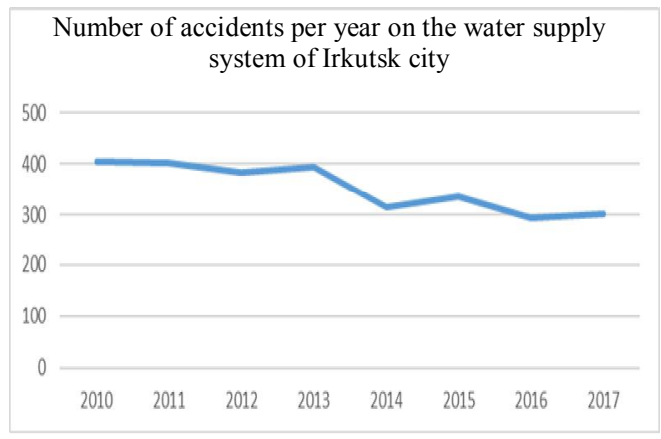

a)

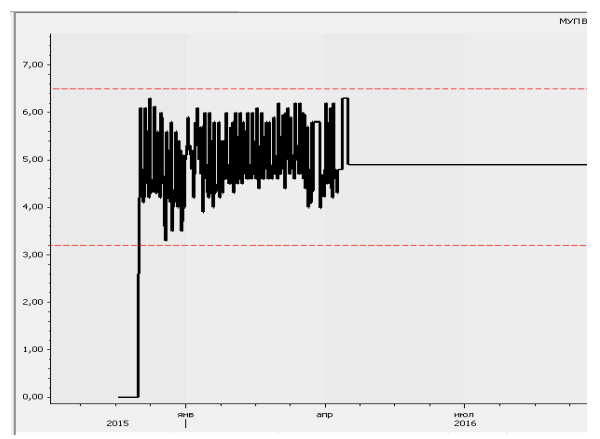

b)

Fig.2. Curve a) shows the number of accidents in Irkutsk WSS per year; b) displays the pressure change in one of network nodes before and after the pressure regulator installation.

ICC is also used for advance planning of repair work. Engineers calculate hydraulic conditions and work out all the variants of switching-off. The order of valves closure is made. The list of consumers with full and partial restriction of water supply is created. To facilitate the work, the ICC allows you to display only those node schemas in which the switching-off are made. After that, the network fragment is printed and sent to the management for agreement. Such a study of the repair plan on the electronic model also contributes to the rising of the system reliability.

\section{Conclusions}

The analysis of the problem of ensuring the WSS reliability shown that the problem of analysis and ensuring reliability requires time-consuming, multivariate calculations of the WSS hydraulic operating conditions in both design and operation.

The brief description of the new version of ICC "Angara-WS" is given. The feature of this ICC is the possibility of carrying out multi-level calculations of almost any dimension WSS, as well as effective analysis and maintenance of operational reliability of real systems.

The characteristic of the experimental and industrial operation of the ICC in the framework of the automated working station of the operation conditions calculation engineers is given. The main results obtained with his help is presented. The use of ICC for the analysis of the permissibility of the existing hydraulic regimes and the development of the events to ensure the reliable operation of the Irkutsk WSS is shown. 


\section{References}

1. S.V. Khramenkov, O.G. Primin, About the reliability of water-bearing pipelines and the planning of their recovery (2013http://трубопровод.рф/статьи/все/2013/11/7/oнадежности-водонесущих-трубопроводов) [in Russian]

2. Building rules SP 31.12330.2012, Water supply. External networks and facilities (LLC ROSEKOSTROY, JSC Construction Research Center, Moscow, 2012) [in Russian]

3. M.A. Somov, M. G. Zhurba, Water supply. Voluime 1. Water intake, supply and distribution systems (ASV, Moscow) [in Russian]

4. Yu.A. Ilin, Calculation of reliability for water supply (Stroiizdat, Moscow, 1987) [in Russian]

5. E.M. Galperin, N.V. Shapkin, Water supply and sanitary technique, 8, 28 (2013) [in Russian]

6. Yu.A. Yermolin, M.I. Alekseev, Water supply and sanitary technique, 5, 68(2016) [in Russian]

7. O.G. Okeola, S.O. Balogu, Estimating a municipal water supply reliability (http://dx.doi.org/10.1080/23311916.2015.1012988)

8. V.R. Chupin, A.S. Dushin, Water supply and sanitary technique, 12, 35 (2017)

9. V.S. Ignatik, S.V. Sarkisov, P.A. Putilin, The Eurasian Union of Scientists (EUS), 4 (13), 49 (2015)

10. M. Maglionico, R. Ugarelli, Reliability of a water supply system in the quantity and quality terms (http://studylib.net/doc/8739084/reliability-of-a-water-supply-system-inquantity-and- qual ...)

11. M.B. Javanbarg, S. Takada, Seismic reliability assessment of water supply systems (http://www.academia.edu/5402910/Seismic_Reliability_Assessment of Water_Supply Systems)

12. D. G. Yoo, D. Kang \& J.H. Kim, Reliability Engineering and System Safety, 146, 79 (DOI: 10.1016 / j.ress.2015.10.001, 2015)

13. https:/www.epa.gov/water-research/epanet

14. N.N. Novitskiy, A.V. Alekseev, The Eleventh International Conference Computing and control for the Water Industry, 3, 901 (2011)

15. http://51.isem.irk.ru/angara

16. A.V. Alekseev, N.N. Novitsky, Science bulletin of NSTU 2, 26 (2017) [in Russian]

17. N.N. Novitsky, M.G. Suharev, e.t.c. Pipeline systems of Energy (Sciense, Novosibirsk, 2015) [in Russian]

18. A.V. Alekseev, N.N. Novitsky, S.Yu. Obuzdin, Water supply and sanitary technique, 11, 64 (2017) [in Russian]

19. N.N. Novitsky, M.G. Suharev, e.t.c. Pipeline systems of Energy (Sciense, Novosibirsk, 2017) [in Russian]

20. N.N. Novitsky, A.V. Alekseev, O.A. Grebneva, A.V. Lutsenko A. V., V.V. Tokarev, Z.I. Shalaginova. Energy (https://doi.org/10.1016/j.energy.2018.02.070) (in press)

21. A.V. Alekseev, N.N. Novitsky, R.V. Chupin, V.R. Chupin, Water supply and sanitary technique, 11, 26 (2017) [in Russian]

22. A.V. Alekseev, N.N. Novitsky, S.Yu. Obuzdin. Water supply and sanitary technique, 11, 54 (2017) [in Russian]

23. A.V. Kurtin, Water supply and sanitary technique, 11, 72 (2017) [in Russian] 